Tópico de Interesse Geral

\title{
Técnicas anatômicas no ensino da prática de anatomia animal ${ }^{1}$
}

\author{
Fabio Sergio Cury ${ }^{2}$, Julia Barrionuevo Censoni ${ }^{3}$ e Carlos Eduardo Ambrósio ${ }^{3 *}$
}

\begin{abstract}
Cury F.S., Censoni J.B. \& Ambrósio C.E. 2013. [Anatomical techniques in the animal anatomy practice teaching.] Técnicas anatômicas no ensino da prática de anatomia animal. Pesquisa Veterinária Brasileira 33(5):688-696. Departamento de Medicina Veterinária, Faculdade de Zootecnia e Engenharia de Alimentos, Universidade de São Paulo, Av. Duque de Caxias Norte, Pirassununga, SP 13635-000, Brazil. E-mail: ceambrosio@usp.br

The concern about preservation of anatomical specimens in existence for over 5000 years, since the use of anatomical parts, are indispensable for teaching and contribute for the improvement of applicative, assimilative skills and understanding of the discipline. This paper proposes better use of techniques in anatomy laboratories, to abolish the use of formaldehyde as preservative, allowing a pleasant environment for the practice of teaching/learning relationship. For this purpose, we used four anatomical techniques, (1) the cryodehydration, (2) glycerin conservation, (3) latex injection and (4) vinylite injection followed corrosion, we executed using dogs, cats and organs from donations. With cryodehydration and glycerin conservation the anatomical materials were considerably lighter than when kept in formaldehyde, odorless unlike in the use of formaldehyde and other preservatives. The structures to be studied were kept intact, easily to view, and the specimens could be stored in closed boxes without any liquid, thus remaining for up to 3 years. The Injection techniques (latex and vinylite followed by corrosion) showed total efficiency to inject filling systems, and allowed a clear view of all ramifications and paths of the circulatory system. The four anatomical techniques studied were shown to be sufficient to meet the needs of students to study anatomy due to the perfect disclosure of external and internal animal structures.
\end{abstract}

INDEX TERMS: Anatomy, anatomic tecnics, laboratory, conservation.

RESUMO.- A preocupação quanto a conservação de peças anatômicas existe a mais de 5 mil anos, pois o uso de peças cadavéricas são indispensáveis para o ensino, contribuindo com a melhora das habilidades aplicativas, assimilativas e compreensivas da disciplina. Esse trabalho propõe maior utilização das técnicas apresentadas em laboratórios de anatomia, visando abolir o uso do formol como conservante, permitindo um ambiente agradável para a prática da relação ensino-aprendizagem. Para isso foram utilizadas quatro técnicas anatômicas, a criodesidratação, glicerinação, injeção de látex e injeção de vinilite seguido de corro-

\footnotetext{
${ }^{1}$ Recebido em6 de março de 2013.

Aceito para publicação em 17 de abril de 2013.

${ }^{2}$ Departamento de Cirurgia, Faculdade de Medicina Veterinária e Zootecnia (FMVZ), Universidade de São Paulo (USP), Av. Orlando Marques de Paiva 87, Bloco 17, Piso Superior, Cidade Universitária, São Paulo, SP 05508-270, Brasil. *Autor para correspondência: ceambrosio@usp.br

${ }^{3}$ Departamento de Medicina Veterinária, Faculdade de Zootecnia e Engenharia de Alimentos (FZEA), USP, Av. Duque de Caxias Norte 225, Pirassununga, São Paulo, SP 13635-000, Brasil.
}

são, que foram executadas utilizando cães, gatos e órgãos provenientes de doações. Com a criodesidratação e glicerinação os materiais anatômicos ficaram consideravelmente mais leves do que eram quando mantidos em formol, mantendo-se inodoros, diferente do evidenciado na utilização de formol e outros conservantes. As estruturas de estudo das peças ficaram intactas, de fácil visualização e o armazenamento passou a ser feito em caixas fechadas sem qualquer tipo de liquido, mantendo-se assim por até 3 anos. As técnicas de injeção de látex e vinilite seguido de corrosão mostraram total eficiência preenchendo os sistemas injetados, podendo visualizar as ramificações e todo caminho percorrido no sistema circulatório. As quatro técnicas anatômicas estudadas nesse trabalho mostraram ser suficientes para atender as necessidades dos estudantes quanto ao estudo da anatomia, devido à perfeita evidenciação de estruturas externas e internas dos animais.

TERMOS DE INDEXAÇÃO: Anatomia, técnicas anatômicas, laboratório, conservação. 


\section{INTRODUÇÃO}

Cursos laboratoriais possuem grande importância científica para a educação em geral, levando a uma evolução significativa tanto na parte acadêmica quanto na aprendizagem dos estudantes (Yasser \& Tolba 2009).

Tratando-se de laboratórios de anatomia, estes têm como objetivos o estudo de peças anatômicas sintéticas e cadavéricas sendo indispensável o manuseio das mesmas. As peças passam por dissecação e reparação para estudo, sendo conservadas na grande maioria em solução de formaldeído a $10 \%$ ou pela técnica de glicerinação (Freitas et al. 2009).

A preocupação quanto a conservação de peças anatômicas existe a mais de 5 mil anos, pois o uso de peças cadavéricas naturais são indispensáveis para o ensino, sendo um método utilizado em todo o mundo, devido a contribuição no aprendizado prático melhorando as habilidades aplicativas, assimilativas e compreensivas da disciplina preparando os estudantes para uma situação real, além do caráter cientifico acadêmico. A conservação tem como objetivo preservar da maneira mais próxima possível, a morfologia e características das peças como são nos animais vivos, tal como consistência, coloração e flexibilidade. Nos dias de hoje podemos contar com uma grande variedade de técnicas que auxiliam na preservação dos tecidos animais para estudo (Kimura \& Carvalho 2010).

0 formol, cujo é o conservante mais utilizado mostra efeitos destrutivos tanto em tecidos de pequenas estruturas quanto ao DNA segundo estudos citados por Carvalho (2009), dizendo que isso trás consequências na precisão de um estudo morfológico e em análises genéticas, porém se trata de um assunto que se mantém em discussão devido vários estudos que afirmam a não influencia do formol ao DNA.

Quanto a variedade de técnicas anatômicas, temos inúmeras maneiras de executar uma determinada técnica, alterando algumas etapas da metodologia, como algum detalhe diferente no procedimento, substituição, redução ou acrescentando alguns materiais utilizados podemos evidenciar algum sistema de maneira especifica, isso vale também para métodos de conservação. Os protocolos de glicerinação foram as maiores alternativas para a substituição do formol, diferentes protocolos foram e são utilizados na tentativa de chegar a $100 \%$ de confiança quanto sua eficiência, sendo utilizado na maioria dos procedimentos o álcool absoluto associado a glicerina. 0 fato de essa substância ser inodora a preocupação quanto a irritação das mucosas não existe, além do fato de não ser uma substância cancerígena e ter o nível de contaminação muito inferior ao do formol quanto ao meio ambiente. A glicerina passou a ser utilizada devido à sua ação fungicida e bactericida, deixando também a coloração que ela dá as peças mais próximas do real, maior leveza devido a desidratação que a técnica causa, longo período de conservação e possibilita fácil visualização e identificação de estruturas detalhadas. Como desvantagem essa técnica mostra um custo consideravelmente elevado, dados mostram um custo de no mínimo $\mathrm{R} \$ 0,52$ o litro de formol, enquanto a glicerina mostra no mínimo um valor de $\mathrm{R} \$ 5,36$ o litro, sendo esse o motivo de ainda não ter sido padronizada em todas as universidades (Krug et al. 2011).
Além do uso do formol e da glicerina cujo são as técnicas mais conhecidas e utilizadas devido a maior aproximação das características reais das peças, existe uma técnica de ótima alternativa na conservação de peças individuais e animais inteiros, conhecida como criodesidratação (Kremer et al. 2011). Como o próprio nome já diz, a técnica de criodesidratação consiste em desidratar as peças para serem utilizadas em sala de aula, de maneira que essa técnica surgiu na tentativa de solucionar o problema da conservação e manutenção de peças anatômicas em formol, pois independente da concentração é uma solução extremamente desagradável quanto ao odor que também desencadeia uma grande irritação a garganta, pulmões, olhos, nariz e até mesmo ao entrar em contato com a pele. Isso trás uma limitação considerável no estudo da anatomia, sendo um fator de desestímulo aos estudantes, professores e até mesmo aos funcionários de laboratório. A retração dos tecidos é uma característica inevitável na técnica de criodesidratação devido a total perda de água da peça utilizada, porém não é considerado um fator de grave influencia no estudo dos alunos, mostrando apenas uma pequena deformação em algumas estruturas devido a retração tecidual (Freitas et al. 2009). Além da vantagem de não ser necessário manter as peças anatômicas em soluções fixadoras, a perca total de água das mesmas faz com que fiquem extremamente mais leves, tornando o transporte mais simples (Taylor \& Van Dyke 1995).

Dessa maneira, ao utilizar uma técnica assim, podemos obter a conservação de peças de estudo anatômico para diferentes finalidades, sendo possível estudar a dimensão dos órgãos tal como a relação de sintopia entre eles, mantendo a cor, formato e posição desejada. Deve-se levar em consideração também o custo mais acessível para a utilização da técnica, a facilidade de execução, a não necessidade de fixadores como o formol para manutenção e conservação, a conveniência quanto ao peso das peças e o longo tempo de duração do material para estudo (Miranda-Neto 1990, Rodrigues 1993, Di Dio 2002).

As técnicas de preenchimento consistem em injetar desde vasos sanguíneos, linfáticos e biliares até urinárias, reprodutoras e brônquios. Para essa técnica o látex natural, borracha siliconada e polímeros como o acetato de vinila foram e são os produtos de maior aceitação pelos anatomistas, devido o alto grau de penetração que fazem em até mesmo capilares. Uma grande vantagem dessas técnicas é o fato dos vasos não serem alterados quanto sua espessura, não causando retração ou dilatação, pois a substância bem adaptada percorre todo o sistema circulatório de maneira a substituir o sangue. 0 látex é o material mais conhecido e aceito para essa técnica, podendo ser sintético, natural ou neoprene, sendo adquirido na sua cor natural branca e podendo ser pigmentado de qualquer cor. A técnica de preenchimento por vinilite é um procedimento que necessita da corrosão do tecido orgânico da peça estudada para ser possível a visualização dos ductos e sistemas devidamente preenchidos pelo acetato de vinila. Para a corrosão o ácido clorídrico é a substância mais viável e utilizada (Rodrigues 2010).

A utilização de técnicas anatômicas mais modernas e viaveis em laboratórios de anatomia animal visa maior éti- 
ca aos animais e ao meio ambiente, facilitando também a aprendizagem significativa na área para o uso e aceitação de um laboratório ideal para os alunos e funcionários a fim de contribuir e fornecer um melhor ambiente de estudo, além de tornar o Brasil um país comparativo aos de primeiro mundo quanto a planos de aula.

\section{MATERIAL E MÉTODOS}

Para a execução das técnicas e análise morfológica das peças anatômicas foram utilizados cães e gatos provenientes de clinicas veterinárias, cujo ao entrarem em óbito foram doados por seus respectivos donos, sendo no total utilizado um gato para criodesidratação do ventrículo gástrico e injeção de vinilite e quatro cães sendo dois para criodesidratação, um para injeção de látex e um para injeção de vinilite e criodesidratação do ventrículo gástrico. Os animais foram transportados para o Laboratório de anatomia animal no departamento de Ciências Básicas da FZEA/ USP e preparados para a realização das técnicas. Foram utilizadas peças anatômicas (órgãos) do laboratório de anatomia animal do departamento de ciências básicas (ZAB) FZEA/USP sendo especificamente: um coração, um rim, um encéfalo de bovino e um rim de equino utilizados para a glicerinação e um ventrículo gástrico de equino e um de suíno para criodesidratação. Após a fixação, realização das técnicas e dissecação dos animais, as peças foram fotografadas mostrando os resultados obtidos.

\section{Glicerinação}

Os órgãos antigos utilizados (um coração, um encéfalo e um rim de bovino e um rim de equino) eram preservados em formol a $10 \%$, foram constantemente lavados apenas com água por um período de 48 horas para a total retirada do formol presente nas peças, as quais em seguida foram levadas para secarem em sombra. Posteriormente, as peças foram mantidas submersas em peróxido de hidrogênio a $10 \%$ por 48 horas em um recipiente fechado. As peças foram retiradas da solução, lavadas em água e secas de maneira natural à sombra.

Após isso as peças ficaram submersas em álcool absoluto (99\%) em um recipiente fechado, sendo medida com um alcoômetro a concentração do álcool uma vez por semana até que essa concentração chegasse a $65 \%$, processo que leva no mínimo dois meses e meio para ser concluído. A permanência no álcool faz com que as peças fiquem desidratadas quase por completo, processo essencial para o sucesso da técnica.

Ao serem retiradas do álcool esperou-se a secagem das peças novamente à sombra. Para a finalização da técnica as peças ficaram submersas em glicerina P.A. durante 2 meses. A glicerina tem por sua vez a função de hidratar as peças alteradas pelo álcool e trazer de volta a cor que foi removida pelo peróxido de hidrogênio, agindo como um reparador dos danos causados pelas substâncias anteriores. Após esse período, as peças foram retiradas da glicerina e deixadas em um escorredor por um período de no mínimo 8 horas, para que o excesso de glicerina seja retirado.

\section{Látex}

Foi utilizado látex natural branco juntamente com o corante líquido de pigmentos vermelho, azul e verde representando respectivamente artéria, veias e sistema porta. 0 látex foi muito bem agitado antes de cora-lo para obter-se completa homogeneização do produto, e após dada a pigmentação desejada filtrado para a retirada de grânulos maiores formados no látex, os quais poderiam obstruir algum vaso, impedindo o sucesso da técnica. Foi dissecada no lado esquerdo a artéria carótida comum e a veia jugular de um cão e ambas receberam cânulas para com uma seringa de $20 \mathrm{ml}$ o látex ser aplicado.

Primeiramente foi feito a injeção da artéria carótida comum no sentido caudal do animal, de maneira que foi aplicado o látex até podermos ver a gengiva mostrar tons de vermelho. Após isso, foi retirada a cânula da artéria e logo em seguida utilizado acido acético glacial no local onde a cânula foi inserida causando a coagulação do látex para não ocorrer extravasamento ao retirar a cânula. Logo após foi feito o mesmo procedimento na veia jugular, porém com o látex azul e no sentido cranial. 0 látex azul foi injetado no animal até podermos visualizar vasos do pênis ficarem corados e para a certificação total de que o látex correu pelo animal todo, foi feito uma pequena incisão no metacarpo direito para visualizarmos se os vasos superficiais dessa região estavam corados.

Para a injeção do sistema porta foi feita uma incisão no centro da região abdominal do animal (linha Alba) de maneira a termos acesso ao intestino. Com uma seringa de $20 \mathrm{ml}$ foi injetado o látex pigmentado de verde na veia mesentérica inferior até podermos visualizar a entrada da veia porta no fígado ser corada de verde. Para total segurança da solidificação do látex, esperou-se passar um período de 24 horas após a injeção para iniciar a dissecação do animal.

\section{Vinil seguido de corrosão}

Na execução desta técnica é necessário o uso de órgãos frescos, sendo assim foram utilizados dois pulmões, sendo um de gato e outro de cão. A cavidade torácica dos animais foi aberta com bisturi e com o auxílio de um alicate cirúrgico foi feita a retirada das costelas. Logo após, os pulmões foram retirados dos animais deixando a traqueia quase toda preservada.

Ao retirar os pulmões de maneira extremamente cuidadosa para não lesionar nenhum lobo pulmonar, foi retirado o coração. Após isso os pulmões foram lavados externamente e internamente com água inserindo-a pela traqueia, seguida da pressão cuidadosa dos lobos pulmonares da periferia em direção ao hilo. Esse procedimento ocorreu várias vezes até notar que o órgão não expelisse mais secreções. Os pulmões então ficaram submersos em álcool a $80 \%$ por 24 horas e logo após colocado uma cânula grossa de silicone bem adaptada em cada traqueia, sendo amarrados com barbante no local acoplado garantindo a firmeza da cânula. Para a fixação dos órgãos foi produzida uma corrente de ar continua na árvore brônquica através do tubo de silicone, cujo ar passou por um recipiente contendo álcool e formol sendo $50 \%$ de cada, e ao passar por este recipiente levava o vapor da solução fixadora até os pulmões, durando algumas horas até todos os lobos pulmonares ficarem em tonalidade branca e com distensão semelhante à forma dos vivos durante a inspiração.

0 acetato de vinila em pó foi preparado sendo diluído em acetona P.A. e bem agitado até a solução mostrar certa viscosidade, após o preparo, a solução transparente foi corada com tinta automotiva vermelha, no geral segue-se os mesmos padrões de cores empregados no látex, sendo vermelho para artérias e azul para veias, porém foi feito a injeção da arvore brônquica dos animais. Após ser pigmentada, a solução foi inserida nos pulmões via traqueia com uma seringa de $60 \mathrm{ml}$ até os lobos pulmonares serem totalmente preenchidos, a abertura da traqueia foi fechada amarrando-se um barbante.

Os pulmões foram mantidos submersos em água por 24 horas para auxiliar a solidificação da solução de vinilite, após esse processo os pulmões foram levados separadamente para recipientes plásticos onde ficaram submersos em ácido clorídrico P.A. por 12 horas. Após retirados do ácido, foram lavados para a retirada de possíveis restos de tecidos nos lobos pulmonares, com isso já 
pode-se evidenciar toda parte interna da árvore brônquica pulmonar.

Ao certifica-se que os pulmões estavam completamente secos, foi feita a pintura das estruturas com tinta spray vermelha automotiva, e logo após a secagem a envernização com spray automotivo, a fim de garantir proteção das estruturas. Caixas de vidro individuais foram feitas sob medida para a permanência das estruturas à longo prazo, visando o aumento de proteção.

\section{Criodesidratação}

Foram utilizados quatro ventrículos gástricos de diferentes espécies (felino, canino, suíno e equino) sendo um de cada espécie, utilizando dois já fixados em formol a 8\% (Suíno e Equino) e dois frescos (Canino e Felino). Os ventrículos gástricos foram retirados dos animais de maneira a deixar preservados alguns centímetros do esôfago e também do duodeno. Após dissecar os órgãos, a extremidade do duodeno de cada um foi amarrada com barbante fechando completamente qualquer passagem. Após isso foi injetado ar nos ventrículos gástricos pela cárdia dos órgãos utilizando-se uma bomba manual, inflando-os o máximo possível e para que o ar se mantivesse dentro dos órgãos foi dado outro nó com barbante fechando também a cárdia por onde foram inflados os ventrículos gástricos.

Os ventrículos gástricos foram amarrados em um bastão de madeira (usado como um varal) e levados a um container refrigerado a menos 8 graus Celsius. Foram feitas baterias repetidas mantendo-os 48 horas congelados e 24 horas a temperatura ambiente para o descongelamento dos órgãos, essas repetições foram feitas por 6 vezes nos menores (canino e felino) e 8 vezes nos maiores (equino e suíno). A cada descongelamento o volume dos órgãos diminuía, sendo assim o barbante do esôfago era desamarrado e novamente era feito o enchimento dos órgãos com ar para mantê-los sempre bem inflados. No momento de infla-los novamente notava-se a perda de elasticidade, devido a desidratação. Finalizados, os órgãos passaram a ser mantidos fechados em caixas de vidro transparente feitas sob medida proporcionais ao tamanho de cada ventrículo gástrico para a proteção e melhor manuseio.

Também foram utilizados dois cães, sendo que ambos foram fixados em formol a $8 \%$ e fixados em um plano de madeira de forma que foram mantidos in situ (em pé). Os animais foram dissecados de maneira a vermos a musculatura. Logo após, foram abertas janelas nas regiões torácicas e abdominais para visualizarmos internamente o posicionamento dos órgãos. Após essa etapa, os animais passaram pelo mesmo processo citado acima para que ocorresse a criodesidratação dos mesmos, sendo congelados e descongelados por 10 vezes.

\section{RESULTADOS E DISCUSSÃO}

\section{Glicerina}

Ao passarem pela etapa do peróxido de hidrogênio, as peças se mostraram claras e consideravelmente mais rígidas em relação à conservação em formol (Fig.1A,D e 2A,D). Após a permanência em álcool absoluto, a leveza e rigidez dos órgãos aumentaram drasticamente, devido à perda de água, demonstrando-se ainda quase tão claras quanto ao passarem pelo peróxido e bem ressecadas (Fig.1B,E e 2B,E).

Finalizada a técnica, os órgãos se mostraram mais maleáveis e de tonalidade menos opaca comparadas a peças conservadas e formol, tornando-as mais próximas de peças frescas (Fig.1C,F e 2C,F). Não foi evidenciado nenhum tipo de queda de resistência das peças, mantendo-se resistentes e de aspecto semelhante a um "emborrachado", as quais facilitam o seu manuseio. Os materiais anatômicos ficaram consideravelmente mais leves do que eram quando mantidos em formol, isso acontece devido à desidratação causada pelo álcool absoluto, também não demonstraram odor forte, mantendo-se inodoros, diferente do evidenciado na utilização de formol e outros conservantes.
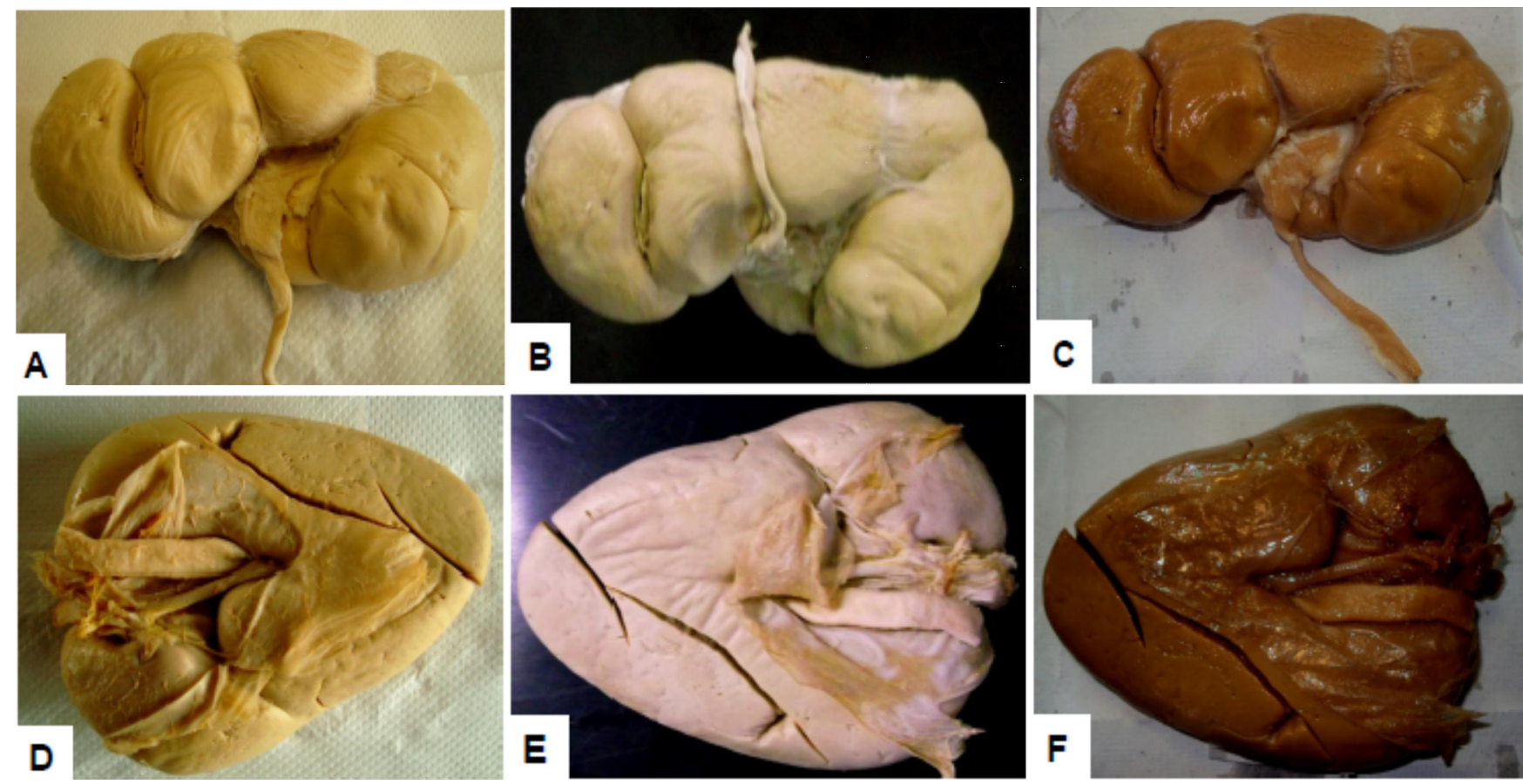

Fig.1. (A) Rim de bovino após ser retirado da água oxigenada. (B) Rim de bovino após permanência no álcool absoluto até a marcação de 65\% de concentração. (C) Rim de bovino glicerinizado. (D) Rim de equino após 48 horas em água oxigenada. (E) Rim de equino após ser retirado do álcool absoluto. (F) Rim de equino glicerinizado. 

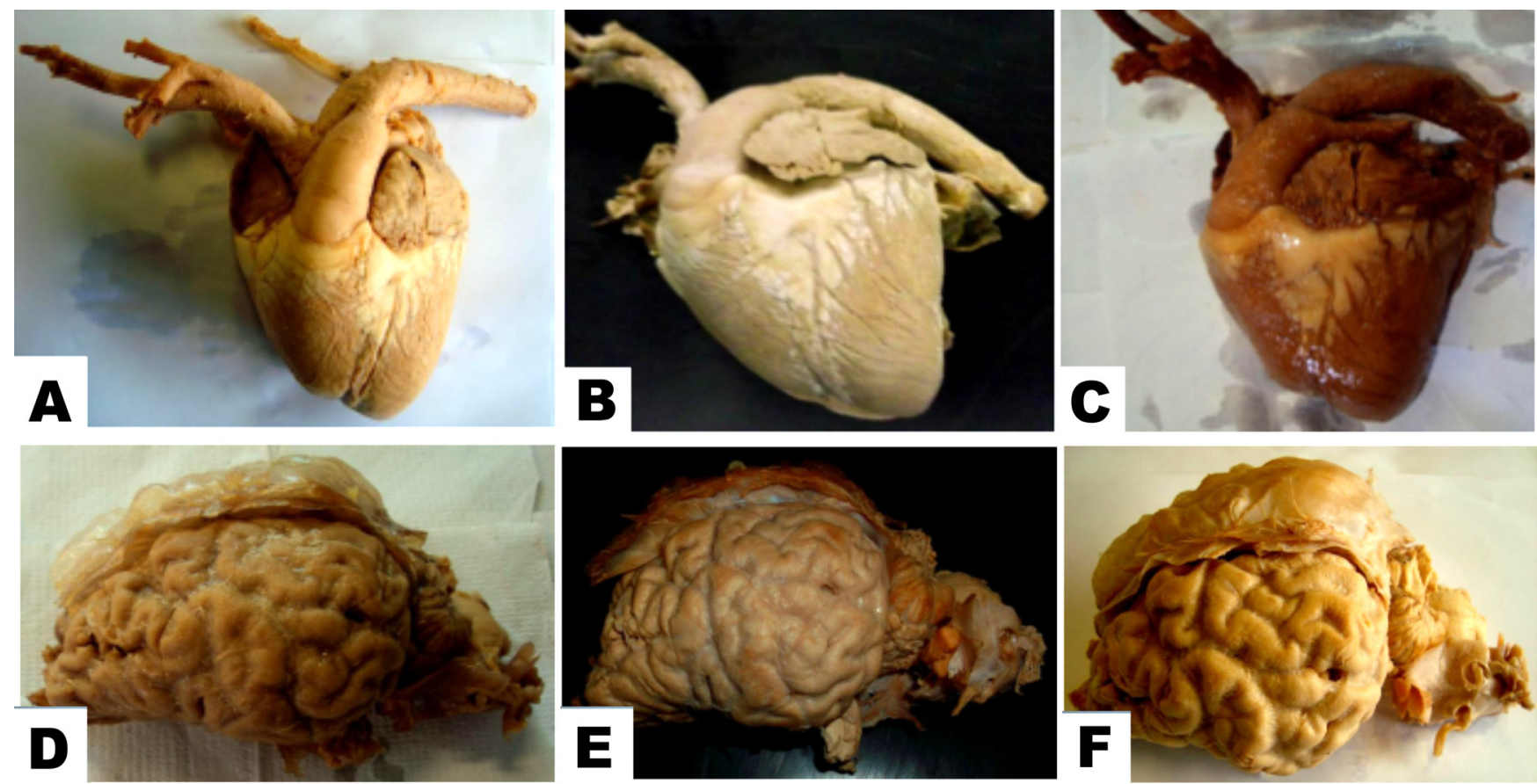

Fig.2. (A) Coração retirado da água oxigenada. (B) Coração retirado do álcool absoluto. (C) Coração glicerinizado. (D) Encéfalo após 48 horas em água oxigenada. (E) Encéfalo após ser retirado do álcool absoluto. (F) Encéfalo glicerinizado.

As estruturas de estudo das peças mantiveram-se intactas, de fácil visualização, manuseio e armazenamento, pois passaram a ser mantidas em caixas fechadas sem qualquer tipo de liquido, mantendo-se assim intactas por períodos de 2 anos e 6 meses a 3 anos. A manutenção das peças foram feitas após períodos de 2,5 a 3 anos, apenas deixando-as submersas em glicerina P.A durante 5 dias. Um detalhe importante é que a glicerina escorrida acumulada pode ser usada novamente para fazermos novas peças, sendo um produto de altíssimo rendimento. Vale ressaltar que a técnica pode ser aplicada em animais inteiros, basta antes fazer a fixação interna do animal com formol a 8\% introduzindo através de uma cânula na artéria carótida comum. Após esse processo de fixação, o animal pode ser dissecado de maneira a observar-se o sistema desejado, e a técnica pode ser aplicada exatamente da mesma maneira descrita com os órgãos acima.

Apesar de apresentarem um protocolo diferente Carvalho et. al (2013) ao fazer a técnica de glicerinação com glicerina semipurificada tiveram resultados semelhantes aos apresentados nesse trabalho, pois as peças também tiveram diminuição de peso, de odor, flexibilidade, estruturas anatômicas intactas e passaram a ser conservadas a seco, porém as peças de Carvalho et. al (2013) ficaram em tonalidade amarelada devido a cor da glicerina semipurificada utilizada.

Dias et al. (2006) afirmam que a glicerina a 50\% associada ao cloreto de sódio a $30 \%$, mostra maior eficácia na conservação das peças anatômicas, não deixando ocorrer contaminação por microorganismos nas mesmas, ressaltando que mesmo sem qualquer concentração de glicerina o cloreto de sódio continua mostrando eficiência na conservação e que qualquer concentração de glicerina mesmo a 50\% não mostra eficiência se não estiver associada ao cloreto. Entretanto, os dados demonstram total eficácia no protocolo de glicerinação apresentado, sem a necessidade do uso de cloreto de sódio, sendo suficiente apenas a utilização da glicerina P.A., pois a fase de maior importância da técnica está no período de tempo em que as peças permanecem no álcool absoluto.

Nossos resultados se assemelham aos citados por Gigek et al. (2009) os quais mostram maior eficiência da glicerina em relação ao formol devido a diminuição de peso, odor e também por apresentarem ótimo aspecto estético, semelhante à morfologia original das peças, podendo-se evidenciar com clareza as estruturas dos materiais estudados. Apesar da semelhança dos resultados, Gigek et al. (2009) também apresentaram um protocolo diferente de glicerinação, pois mantiveram as peças em álcool etílico a $70 \%$ por 7 dias ao invés de álcool absoluto por 2 meses e meio, também mantiveram as peças por 7 dias em peróxido de hidrogênio a $3 \%$ e por fim em glicerina $98 \%$ misturada a álcool absoluto por 15 dias.

\section{Látex}

A retirada das costelas facilitou seguirmos o caminho da aorta, assim podendo visualizar as diferentes ramificações e dimensões dos vasos conforme a pigmentação do látex injetado percorreu nos sistemas do animal, evidenciando as artérias e suas respectivas veias. A visualização do sistema porta ficou bem evidente, mostrando desde suas ramificações em todo mesentério (Fig.3A) até a entrada da porta no fígado (Fig.3B) onde ao dissecar o órgão no animal foi possível a visualização do caminho que o sangue percorre do sistema porta até a veia cava caudal (Fig.3D).

0 látex percorreu todo o animal deixando evidente a coloração de veias e artérias entrando e saindo de seus respectivos órgãos, tornando de grande facilidade a visualiza- 

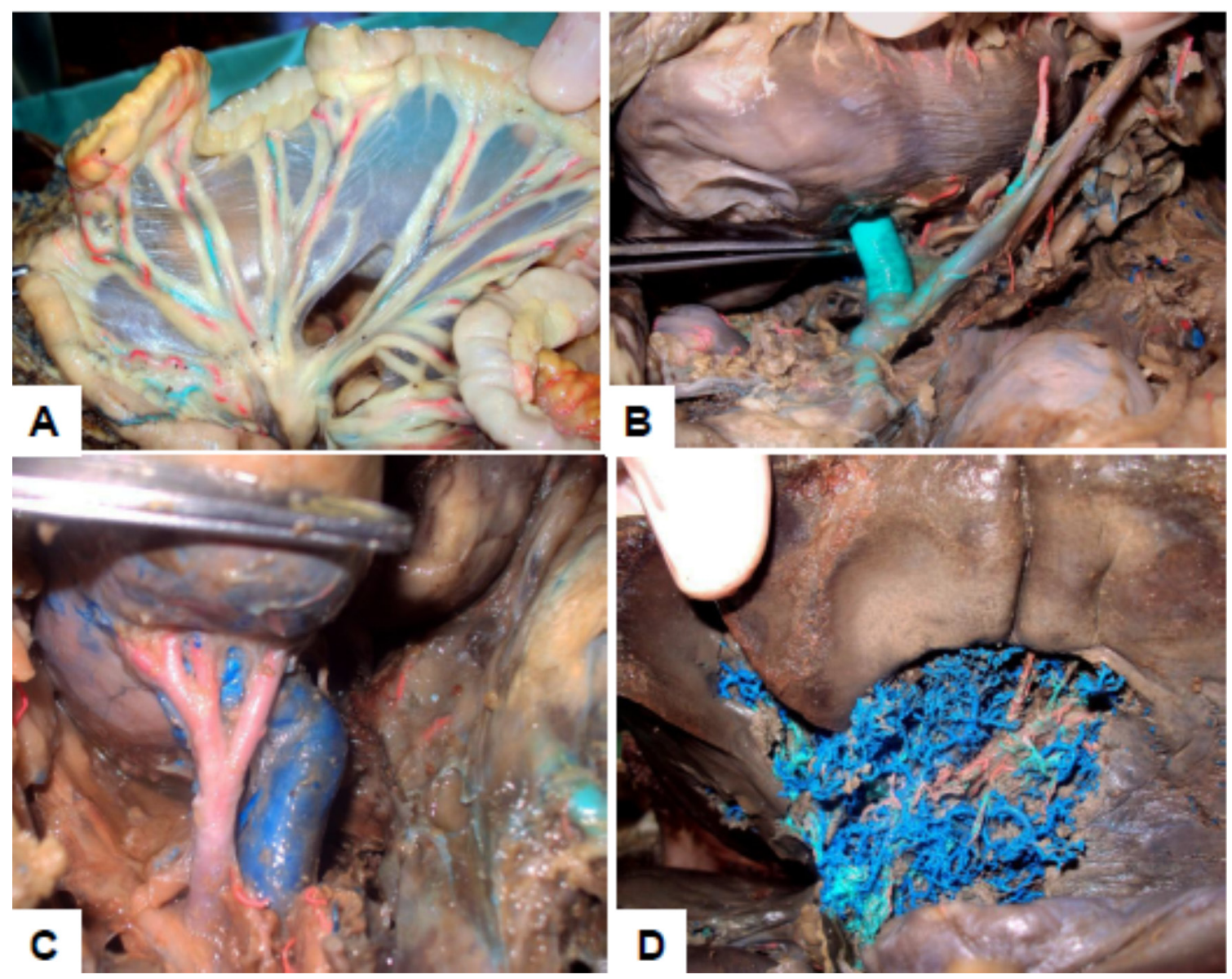

Fig.3. (A) Vasos do mesentério intestinal preenchidos, veias artérias e ramificações da porta hepática. (B) Veia porta hepática (verde) se adentrando no fígado. (C) Artéria (vermelho) e veia renal (azul), podendo-se visualizar o órgão também preenchido. (D) Circulação hepática arterial, venosa e porta, podendo-se evidenciar o direcionamento das ramificações da porta para a veia cava caudal.

ção tanto de vasos intra-abdominais como os intestinais, curvaturas estomacais, rins (Fig.3C), fígado, pulmões e coração, quanto vasos superficiais como veias arco-hióide, facial, maxilar, cefálica, safena, artérias subclávia e femoral.

A técnica de injeção de látex pode ser executada de várias maneiras diferentes devido à variedade de vasos a serem canulados. A técnica aplicada por Oliveira et al. (2000) para visualização dos vasos de Cebus apella foi empregada canulando-se a aorta do animal no sentido tanto cranial quanto caudal, fazendo-se a perfusão do sangue com água morna a $40^{\circ} \mathrm{C}$ antes de ser feito a injeção do látex. Apesar de utilizarmos métodos diferentes para a execução da técnica, os resultados foram semelhantes na evidenciação precisa dos vasos.

Rodrigues (1998) cita que para maior sucesso na injeção de látex chegando até mesmo a preencher capilares é necessário iniciar a injeção com o látex consideravelmente diluído com água, deixando o látex tão fluente quanto a mesma, e após algumas aplicações passar a injetar o látex não diluído, porém existe os riscos quanto ao cuidados para conservar a função de solidificação do látex. No presente estudo não foi feito nenhum tipo de diluição do látex, apenas muita homogeneização do produto seguida de coação, o fato de aplicar a técnica o mais rápido possível após o animal for a óbito tem grande influência no sucesso do resultado.

\section{Vinil seguido de corrosão}

A árvore brônquica se mostrou bem sólida e preenchida, podendo assim visualizar as ramificações da traqueia em brônquios principais (Fig.4B) e todos os lobos pulmonares, inclusive o lobo acessório (Fig.4A). A técnica nos permitiu evidenciar até mesmo bronquíolos aglomerados. A pintura externa das estruturas seguida de envernização se mostrou muito eficiente contra o acúmulo de sujeira e insetos, porém para mante-las completamente seguras e conservadas foram colocadas em caixas de vidro lacrado feitos sob medida para as estruturas. A visualização continuou sendo clara e de fácil manejo devido à transparência do vidro e sua resistência.

Estudos comparativos entre látex e acetato de vinila mostram que em ambas as técnicas existem vantagens e desvantagens, sendo o látex de maior eficiência na visualização de estruturas mais calibrosas e o acetato de vinila sendo mais eficiente tratando-se de pequenos detalhes vasculares, conseguindo percorrer e entrar com maior facilidade em vasos de pequenos calibres devido a solução ser mais fluida (Calomeno et al. 1987). 

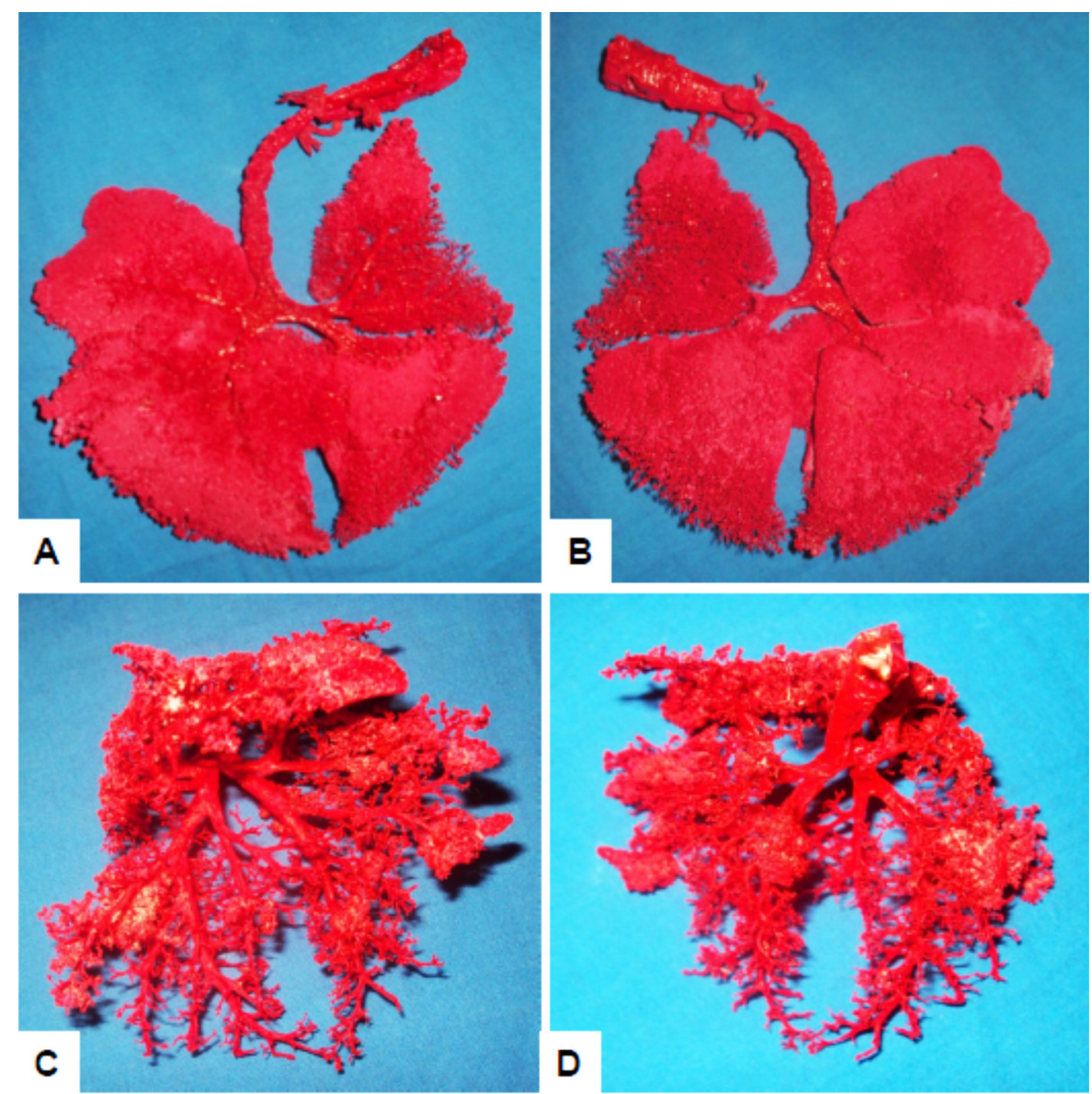

Fig.4. (A) Pulmão de canino (vista ventral), podendo-se evidenciar o lobo acessório. (B) Pulmão de canino (vista dorsal) evidenciando as ramificações brônquicas. (C) Pulmão de felino (vista ventral). (D) Pulmão de felino (vista dorsal).

Abuchaim et al. (2009) ao fazer a técnica de injeção de polímero seguida de corrosão com ácido clorídrico em corações visando determinar a circulação coronária predominante e suas anastomoses, utilizaram o acrílico colorido liquido ao invés do acetato de vinila e afirmou que o polímero mostra resultados tão favoráveis quanto o pó. Tsikaras et al. (1985) também afirmam que polímeros como acrílicos, acetato de vinila e resinas acrílicas são perfeitos para evidenciar sistemas internos em técnicas de injeção seguidas de corrosão, mostrando também eficiência quanto ao fácil acesso e aplicação do material, resistência e durabilidade.

\section{Criodesidratação}

As peças mostraram perda total de água devido ao congelamento e descongelamento excessivo e repetitivo, deixando-as sólidas, rígidas e muito leves. Por outro lado, essa técnica acarretou numa fragilidade considerável das peças submetidas ao procedimento, podendo ser partidas ao receberem algum forte impacto ou queda. Por esse motivo os ventrículos gástricos foram acondicionados em caixas de vidro para proteção a eventuais acidentes de manejo, além de contato com poeira e insetos (principalmente a traça) que podem passar a se alimentar das estruturas. Somado a este fato, ao pincelarmos uma fina camada de glicerina P.A nas peças como um processo de envernização, elas passaram a repelir melhor os insetos além de adquirir uma coloração mais próxima do que eram antes de serem desidratadas.

0 fato dos ventrículos gástricos de canino (Fig.5A) e felino (Fig.5B) terem sido utilizados a fresco para a técnica, não passando por qualquer processo de fixação, não mostraram alterações ou diferenças no resultado final da técnica comparados aos órgãos de equino (Fig.5C) e de suíno (Fig.5D) cujo estavam fixados em formol antes do procedimento.

A visualização dos órgãos nos cães criodesidratados in situ foi possível devido a abertura de janelas nas cavidades torácicas e abdominais dos animais (Fig.6C). Também ficou evidente a musculatura dissecada (Fig.6A) além de glândulas, vasos superficiais e o timo (Fig.6B). Esse tipo de técnica proporcionou um ótimo material a ser usado na topografia anatômica além de comparativa, facilitando compreensão dos alunos por terem acesso a um exemplar real.

A técnica de criodesidratação pode ser feita tanto em peças frescas quanto em peças que já eram mantidas em formol, porém Hildebrand (1968) afirma que quando a técnica é feita em peças que eram mantidas em formol o cheiro forte continua. Os resultados obtidos no presente trabalho mostram que ao fazer a criodesidratação os órgãos já fixados e conservados em formol não possuíam mais cheiro de formol, ficando completamente inodoras. 


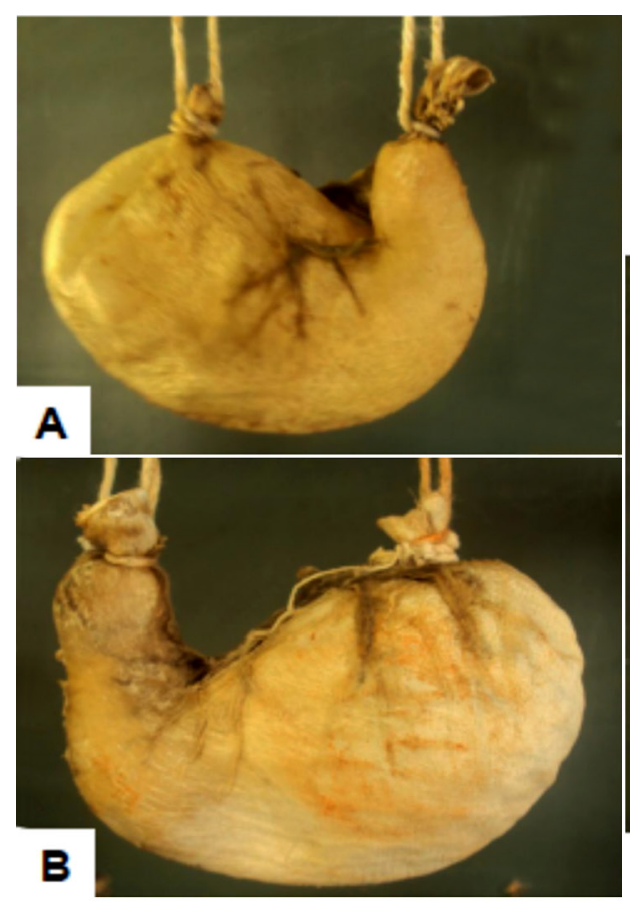

Fig.5. (A) Estômago de felino. (B) Estômago de canino. (C) Estômago de equino. (D) Estômago de suíno.
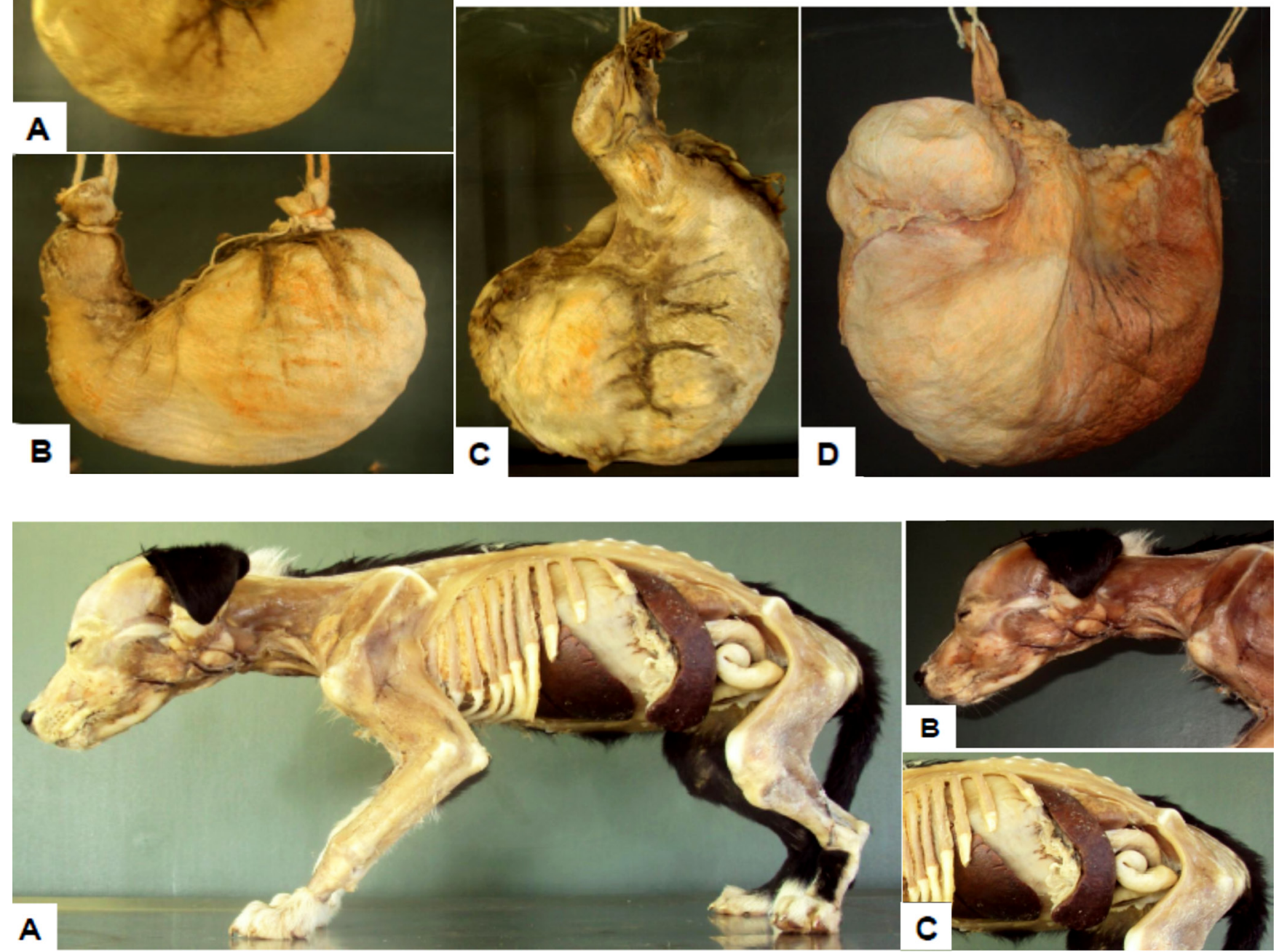

Fig.6. (A) Cão dissecado a esquerda evidenciando o baço, uma pequena porção do jejuno, a região fundica do estomago e fígado e os músculos de toda região dissecada. (B) Cão dissecado evidenciando na cabeça o timo, glândulas, vasos e músculos. (C) Dissecação evidenciando o posicionamento dos órgãos internos e a musculatura da região.

A leveza, rigidez, fragilidade e coloração das peças criodesidratadas foram semelhantes aos citados por Rodrigues em 1998 tanto em órgãos separados quanto a animais inteiros posicionados in situ sendo possível a visualização dos órgãos internos dos animais e após a total desidratação, o fato de ser possível manter o material de estudo apenas refrigerado (não mais congelado) também seguiu conforme citado por Rodrigues.

\section{CONCLUSÕES}

A utilização das técnicas anatômicas apresentadas mostra maior ética com o meio ambiente, fornece melhor didática de estudo e de trabalho para professores, alunos e funcionários, facilita a aprendizagem na área e disponibiliza diferentes tipos didáticos em um mesmo ambiente.

A técnica de conservação em glicerina é mais eficiente que o uso do formol, deixando as peças mais próximas do que eram tanto em tonalidade quanto em maleabilidade, não apresenta cheiro e nenhuma condição prejudicial à saúde, podendo manter as peças de estudo conservadas por décadas aplicando-se a manutenção adequada de 3 em 3 anos.

A técnica de criodesidratação mostra grande eficiência no controle ambiental tratando-se de descarte de resíduos e ótima preservação quanto a conservação tanto de pequenos animais quanto animais de grande porte.

A injeção de látex evidencia perfeitamente o sistema circulatório do material estudado sendo totalmente compatível a com a técnica de glicerinação e criodesidratação.

A técnica de injeção de vinil seguida de corrosão evidenciou perfeitamente a estrutura interna de órgãos complementando as técnicas citadas acima cujo nos permite o estudo externo de animais e demais órgãos. 
As quatro técnicas anatômicas defendidas nesse trabalho além do baixo custo da maioria e grande período de conservação proporcionado, mostraram ser suficientes as necessidades dos alunos quanto o estudo da anatomia, mostrando estruturas externas e internas dos animais, não sendo necessário inúmeras substâncias e materiais para uso de diferentes técnicas que fariam a mesma função.

Agradecimentos.- À CAPES pelo apoio financeiro, à Faculdade de Medicina Veterinária e Zootecnia (FMVZ/USP), São Paulo, pela oportunidade de mestrado na área do presente estudo, à Faculdade de Zootecnia e Engenharia de Alimentos (FZEA), Pirassununga, pelas instalações para desenvolvimento da pesquisa, à veterinária Juliana Barbosa Casals pela doação de animais que morreram em sua clinica, à auxiliar de laboratório da FZEA/USP Lindsay Baltel Paskoski e ao veterinário Paulo Fantinato Neto pela ajuda nos procedimentos das técnicas.

\section{REFERÊNCIAS}

Abuchaim D.C.S., Spera C.A., Faraco D.L., Filho J.M.R. \& Malafaia O. 2009. Coronary dominance patterns in the human heart investigated by corrosion casting. Braz. J. Cardiovasc. Surgery 24(4):514-518.

Calomeno J.G.A., Rohig C.E., Marchesini J.B. \& Brenner S. 1987. A comparison of neoprene latex vs. Vinyl acetate in a study of intra and extrahepatic anatomy of the human liver. Arq. Bras. Cirur. Digestiva 2:39-45.

Carvalho K.S. 2009. Influência do formol utilizado para conservação de cadáveres na obtenção de DNA nuclear em tecido muscular. Dissertação de Mestrado em Odontologia Legal e Deontologia, Faculdade de Odontologia de Piracicaba, Universidade de Campinas, Piracicaba, SP. 66p.

Carvalho Y.K., Zavarize K.C., Medeiros L.S. \& Bombonato P.P. 2013. Avaliação do uso da glicerina proveniente da produção de biodiesel na conservação de peças anatômicas. Pesq. Vet. Bras. 33(1):115-118.

Dias I.C.G., Sant'Ana A.P.F., Saddi L.G.C., Zani F.L. \& Oliveira F.S. 2008. Utilização da glicerina, em diferentes concentrações, associadas ou não ao cloreto de sódio, na conservação de tecidos de ovinos. Universidade Estadual de Maringá (UEM), Maringá, PR, p.1-6. (Resumo)

Di Dio L.J.A. 2002. Tratado de Anatomia Sistêmica Aplicada: princípios básicos e sistêmicos, esquelético, articular e muscular. $2^{2}$ ed. Atheneu, São Paulo.

Freitas I.B., Souza A.M. \& Santos R.M.B. 2009. Técnica anatômica aplicada na conservação de cortes segmentares em Canis familiaris e Decapterus macarellus. IX Jornada de Ensino, Pesquisa e Extensão, UFRPE, Recife, p.1-3. (Resumo) Disponível em <http://www.eventosufrpe.com.br/jepex2009/cd/resumos/R0721-2.pdf> Acesso em 2 ago. 2011.
Gigek T., Oliveira J.E.M., Neto A.C.A., Carvalho W.L. Pereira F.V. \& Almeida A.H. 2009. Estudo Analítico da Técnica de Glicerinação Empregada para Conservação de Peças Anatômicas de Bovinos. Anais V Simpósio de Ciências da Unesp, Dracena, SP, p.1-3. (Resumo)

Hildebrand M. 1968. Anatomical Preparations. University of California Press, Berkeley and Los Angeles. 100p.

Kimura A.K.E. \& Carvalho W.L. 2010. Estudo da relação custo x benefício no emprego da técnica de glicerinação em comparação com a utilização da conservação por formol. Trabalho de Conclusão de Curso de Extensão em Higiene Ocupacional, Universidade Estadual Paulista, Araraquara, SP. 30p.

Kremer R., Schubert J.M. \& Bonfíglio N.S. 2011. Criodesidratação de vísceras do canal alimentar no preparo de peças anatômicas para estudo veterinário. PubVet, Londrina, Ed. 160, Art. 1081. 5(13):1-7. Disponível em <http://www.pubvet.com.br/imagens/artigos/1352011-153445-kremer1081.pdf> Acesso em 26 abr. 2012.

Krug L., Pappen F., Zimmermann F., Dezen D., Rauber L., Semmelmann C., Roman L.I. \& Barreta M.H. 2011. Conservação de Peças Anatômicas com Glicerina Loira. Instituto Federal Catarinense, Concórdia, SC, p.1-6. (Resumo)

Miranda-Neto M.H. 1990. Sobre a Utilização de Adesivo à Base de Polivinil Acetato (PVA) na Preparação de Ossos para Estudos. Universidade de Marília, Marília, SP, p.87-89.

Oliveira A.S., Ferreira J.R. \& Blumenschein A.R. 2000. Estudo anatômico do modelo arterial de vasos responsáveis pelo aporte sanguíneo da glândula submandibular de primatas neotropicais (Cebus apella Linnaeus, 1766). Acta Scientiarum 22(2):573-579.

Rodrigues H. 1993. Técnicas Anatômicas. Imprensa Universitária da UFJF, Juiz de Fora, MG, p.83-107. Ministério da Educação e Cultura, Brasília. 218p,

Rodrigues H. 1998. Técnicas Anatômicas. 2ª ed. Arte Visual, Vitória, ES. $222 p$.

Rodrigues H. 2010. Técnicas Anatômicas. $4^{\text {th }}$ ed. GM Gráfica e Editora, Vitória, ES. 269p.

Taylor W.R. \& Van Dyke G.C. 1995. Revise procedures for staining and clearing small fishes and others vertebrates for bone and cartilage study. Cybium 9(2):107-119.

Tsikaras P.D., Hytiroglou P.M. \& Lazos L.M. 1985. The use of unsaturated polyester resin solutions in preparing casts of renal vessels. Bulletin de l'Association des Anatomistes, Nancy, 69(204):71-78.

Yasser H. \& Tolba E.S. 2009. Educational objectives of different laboratory types: a comparative study. Int. J. Computer Sci. Inform. Security 6(2):89-96. 